\title{
Determination of timing and location of water movement and ice-layer formation by temperature measurements in sub-freezing snow
}

\author{
W. T. PFEFFER \\ Institute of Arctic and Alpine Research, University of Colorado, CB-450, Boulder, Colorado 80309-0450, U.S.A. \\ N. F. HUMPHREY \\ Department of Geology and Geophysics, University of Wyoming, Laramie, Wyoming 82071, U.S.A.
}

\begin{abstract}
Measurements of temperature in snow along a vertical profile during the onset of spring melting are used to calculate spatial and temporal temperature gradients and terms of the conduction equation with an internal energyproduction term are calculated. Heat-transfer information is combined with stratigraphic observations made during melting and allow detailed determination of the timing and location of heterogeneous water movement and of refreezing. Internal energy production is interpreted as latent heat of refreezing of percolated meltwater. Times and locations of flow and refreezing of meltwater are calculated and compared to stratigraphic observations of layering and changes in density and liquid-water content. Sequences of melt, piping, layering and refreezing seen in calculations and in stratigraphy demonstrate retarded flow at fine-to-coarse transitions, flow along such transitions and refreezing at the transitions to form ice layers. Downslope flow is also observed in the absence of an impermeable horizon to redirect flow from the vertical.
\end{abstract}

\section{INTRODUCTION}

The determination of seasonal run-off from snowpacks and glaciers, as well as glacier mass balance from energybalance data, requires the knowledge of routing of meltwater through snow which may be either initially or perennially sub-freezing. The input flux of water at the top of the snow can be measured directly or estimated from measurements of surface-energy transfers (Jordan, 1991; Ohmura and others, 1991). Whether meltwater escapes as run-off or is retained by infiltration and subsequent refreezing in permeable snow is determined by the temperature and physical structure of the snow. Internal refreezing complicates calculations of glacier mass balance and run-off from cold glaciers and ice caps, since the consequences of melt and refreezing persist over time as changes in snow temperature and physical structure which affect water movement in future years Koerner, 1970; Bindschadler, 1985; Pfeffer and others, 1991). Estimates of future sea-level change arising from changed annual run-off from cold glaciers and ice caps are affected by the process of infiltration and refreezing since run-off cannot be simply equated to surface melt. Infiltrated snow declines in permeability as void space fills in by refreezing, and the net effect of the infiltration and refreezing is a lag between the time of onset of increased melt and the time at which the increase in run-off matches the increase in surface melt. Pfeffer and others (1991) showed that this process diminishes the predicted run-off contribution from Greenland under warming conditions by as much as $0.4 \mathrm{~mm}_{\text {year }}^{-1}$ sea-level equivalent.

Snow structure and the location and character of ice layers is also of interest as indicators of warming in ice cores. Ice-core sites are preferably located in areas with minimal or no melt, but most High Arctic core sites experience moderate to occasional melting, and melt layers appear in core records even at high-elevation Greenland sites (Alley and Anandakrishnan, 1995). At warmer low-elevation sites in Greenland and the Canadian Arctic, the occurrence of melt layers may be interpreted as an indicator of warm summers (Koerner and others, 1991), although the actual relation between melt layers and warm melt seasons is more complicated than the simplest analysis would suggest (Koerner, 1970).

Our objective in this paper is to examine in detail the spatial and temporal pattern of infiltration and refreezing of melt for a specific instance of summer melt in cold snow and to describe processes of special importance in subfreezing snow hydrology. We also demonstrate a method for observing heat fluxes appearing in the snow during infiltration and compare those observations to changes in stratigraphy. An understanding of cold-snow processes is critical to realistic modeling of run-off from cold ice masses which experience summer melting, such as the Greenland ice sheet (Pfeffer and others, 1991), and to climatic interpretation of snow and ice stratigraphy (Koerner, 1970). While refreezing phenomena unique to cold snow have been discussed previously (e.g. Müller, 
1962; Colbeck, 1976; Wankiewicz, 1979; Marsh and Woo, 1984a, b), many aspects of cold-snow hydrology have not been described observationally fully or in terms of processes of heat and mass transfer. We focus in this paper on providing observational illustrations of processes acting during infiltration, with particular attention to those aspects of cold-snow hydrology which are different from conventional soils hydrology or snow hydrology at $0^{\circ} \mathrm{C}$.

\section{PREVIOUS WORK}

The structure and occurrence of ice formed on glaciers from refrozen water has been extensively described. Benson (1962), Müller (1962, 1976) and Wakahama and others (1976) have described the percolation and soaked zones or facies, including superimposed ice existing above the equilibrium line and within the soaked facies of non-temperate glaciers. Complications in measurements or calculations of mass balance created by the presence of superimposed ice have been discussed by Sharp (1952), Koerner (1970) and Ambach (1989), among others, and measurements of changes in density profiles at depth are a conventional part of any massbalance survey of a non-temperate glacier (Ostrem and Brugman, 1991). The layered structure of snowpacks is recognized as significant in many aspects of snow-cover physics (Colbeck, 1991) and in the interpretation of ice cores from frequency of ice layers (Koerner, 1970; Braithwaite and others, 1994; Alley and Anandakrishnan, 1995). Detailed observations and analyses of meltwater flow and refreezing have been made using a variety of approaches (e.g. Colbeck, 1976; Marsh and Woo, 1984a, b; Illangasekare and others, 1990; Pfeffer and others, 1990). Conway and Benedict (1994) and Sturm and Holmgren (1993) used methods similar to those described here to calculate refreezing in snowpacks. While the basic physics controlling the interaction between liquid water and sub-freezing snow are understood in a general way, a full understanding of some critical details is lacking which prevents a fully detailed understanding of the process of infiltration and refreezing.

\section{FIELD SETTING}

A site was required with the following features: (1) nontemperate (sub-freezing) ice; (2) a range of glacier facies, including a zone of extensive summer melt, possibly to the point of slush formation; (3) some efficient means of avoiding large areas of slush during the melt season. The Amitsulôq ice cap was chosen on the basis of these criteria. Amitsulôq is a c. $225 \mathrm{~km}^{2}$ ice cap located at $66^{\circ} 07^{\prime} \mathrm{N}, 50^{\circ} 07^{\prime} \mathrm{W}$ on the central west coast of Greenland. Observations were made on the eastern outlet glacier of Amitsulôq, which descends from 1400 to $600 \mathrm{~m}$ in $15 \mathrm{~km}$ and presents facies ranging up to moderate percolation at the ice-cap summit (Olesen, 1982). The relatively narrow width of the last $5 \mathrm{~km}$ of the outlet (approximately $2 \mathrm{~km}$ wide) is bounded by rock. The rocks provided alternate routes of travel up- and down-glacier in the event of extensive slush formation.

The presence of the GGU Tasersiaq research station was a substantial benefit to field operations at Amitsulôq. Living quarters, meteorological and field instruments, and snow machines, were available for use, as well as extensive previous glaciological and meteorological information.

\section{TEMPERATURE MEASUREMENTS IN SNOW DURING INFILTRATION}

\section{Heat-transfer formulation}

The location and structure of ice layers and pipes can be mapped in detail after their formation by careful stratigraphic mapping of snow. It is much more difficult to determine the timing of refreezing. Heat input at the surface can be measured but this is only one of the factors affecting refreezing. Some non-destructive continuous monitoring of pertinent variables must be done to tell when, and where, refreezing occurs.

The method described here involves making temperature measurements in snow during the time that water is moving and refreezing, and calculating spatial and temporal temperature gradients. Comparable measurements have also been made by Conway and Benedict (1994) and Sturm and Holmgren (1993). The terms of the heat-transfer equation can be calculated using spatial and temporal temperature gradients together with adequately accurate expressions for the variable thermal properties of snow. The field procedure for making the measurements is described in the next section. We use the standard conductive-transfer equation of the form (e.g. Arpaci, 1966, equation 2-91):

$$
\rho C \frac{\partial T}{\partial t}=\nabla \cdot\left(k_{\mathrm{th}} \nabla T\right)+q^{\prime}
$$

or in one dimension:

$$
\rho C \frac{\partial T}{\partial t}=\frac{\partial}{\partial z}\left(k_{\mathrm{th}} \frac{\partial T}{\partial z}\right)+q^{\prime}
$$

where $T$ is temperature, $t$ is time, $k_{\text {th }}$ is the bulk effective thermal conductivity of snow, $\rho$ is snow density, $C$ is heat capacity of ice and $q^{\prime}$ is the volumetric rate of local internal energy sources and sinks. The spatial gradient $\nabla T$ is, in general, variable in all three spatial directions.

If the temperature change at a point $(\partial T / \partial t)$ occurs at a rate which is unbalanced by conduction of sensible heat to the point by spatial gradients $(1 / \rho C) / \nabla \cdot\left(k_{\mathrm{th}} \nabla T\right)$ then, in terms of Equation (1), the difference in magnitude between the two terms appears as a heat source or heat $\sin k$, represented by $q^{\prime}$. The term $q^{\prime}$ may include latent heat of fusion during refreezing of liquid water (a heat source) or latent heat of vaporization absorbed during sublimation of solid or evaporation of liquid (a heat sink) or radiant heating in near-surface layers. The term $q^{\prime}$ may also contain a residual arising from errors in the determination of the gradient terms (including unmeasured lateral heterogeneity) or errors in values of the thermal parameters. Potential sources of error must be distinguished from thermal features which represent real phenomena.

Errors in the calculation of $q^{\prime}$ may arise from: (1) 
inaccurate values for density or thermal conductivity, (2) inaccurate finite-difference approximations of derivatives, arising from spatially sparse data, inaccurate temperatures or inaccurate thermistor positions, and (3) temperature-gradient errors, arising from spatially sparse data or gradients unmeasured by a single profile of thermistors. These potential errors may be stationary in time or may change as a consequence of parameters such as density or thermistor position which change over the course of the experiment. Stationary errors can be reduced by examining the distribution of $q^{\prime}$ over depth at the beginning of the experiment when all temperatures were below $0^{\circ} \mathrm{C}$, no melt was being generated and $q^{\prime}$ due to latent heat is known to be zero. A non-zero distribution of $q^{\prime}$ at the beginning of the experiment did exist and appeared to persist as a fixed alias straight across the record. This error is most likely due to inaccuracies in the calculated thermal conductivity as a function of depth. Vertical temperature profiles were measured initially at several laterally distributed positions and initial lateral homogeneity of the temperature field was confirmed. The temperature records that follow were determined from a vertical, one-dimensional profile of thermistors. The initial non-zero distribution of $q^{\prime}$ over depth was subtracted off as an alias signal from the entire record.

Errors in the finite-difference terms, and especially the spatial gradient term, require evaluation of errors in the input values of temperature and thermistor position. A comprehensive error analysis is complicated by the irregular thermistor spacing, which makes the analysis algebraically complex. However, considerable simplification can be achieved by noting that the second spatial derivative and its errors can be written using the following three scaling terms involving errors $\delta T$ (temperature) and $\delta Z$ (thermistor position), ignoring terms of order $\delta^{2}$ and higher:

$$
\frac{\left(\Delta T_{1}-\Delta T_{2}\right)}{\Delta Z^{2}}, \frac{\delta T}{\Delta Z^{2}}, \frac{\delta Z}{\Delta Z} \frac{\left(\Delta T_{1}-\Delta T_{2}\right)}{\Delta Z^{2}}
$$

where $\Delta T_{1}$ and $\Delta T_{2}$ are temperature differences on adjacent intervals and $\Delta Z$ is the scale distance between adjacent thermistor locations. The $\Delta Z$ term is a function of the variable grid spacing and therefore the analysis varies over the grid. The first term gives the scale of the value of the second derivative. The second term scales the error due to uncertainty in temperature $\delta Z$ and the third term scales the error due to uncertainty in position $\delta Z$. The position error is scaled by the ratio of the error in position to the relative positions of the thermistors. Note that, while the error in the thermistor spacing is large in the absolute sense ( 1 or more centimeters in the vertical), the relative position between adjacent thermistors is well known, with relative positions known to approximately $10 \%$ or better of the local thermistor spacing. This contrast between absolute and relative positioning is important and the analysis shows that the second derivative is insensitive to errors in absolute position but highly sensitive to relative position. Since the relative positions are known within approximately $10 \%$, we conclude that position errors in the second derivative are similarly scaled.

The most important error is associated with the uncertainty in temperature $\delta T$. The temperature has an absolute error of $\pm 0.2^{\circ} \mathrm{C}$. From the above error terms, it can be seen that, when the difference between adjacent temperature differences becomes less than the temperature error, then the results have little meaning. In our data, this implies that, as the temperature in the snowpack becomes uniform, the second derivative becomes spurious. Subtle temperature-field curvature in our data will produce questionable results. However, the regions of the temperature field of interest in our discussion of meltwater migration and refreezing are precisely the regions where large spatial and temporal gradients exist and here the analysis is most reliable.

Errors may also arise from unmeasured temperature gradients. In field measurements, we concentrated on achieving the maximum spatial resolution in the vertical dimension at the expense of information on lateral variation. Experience has indicated that initially (before the onset of melt and infiltration) both stratigraphy and temperature are vertically heterogeneous and laterally relatively homogeneous (Gow, 1965; Alley, 1988) and initial stratigraphy and temperature measurements at our site confirmed that initial conditions were laterally very homogeneous. One-dimensional temperature measurements will accurately capture heat fluxes in the initially layered condition and will become progressively less accurate as non-uniform infiltration advances during melt. Uniform horizontal infiltration and refreezing along stratigraphic horizons will preserve lateral homogeneity but vertical infiltration of water via pipes to horizons at depth disrupts lateral homogeneity and introduces horizontal temperature gradients arising from latent heat release at the site of the pipe. Temperatures measured only along a single vertical profile are therefore potentially ambiguous when heterogenous infiltration occurs but certain features inferred from the vertical temperature field cannot be artifacts of unmeasured lateral temperature variations. Specifically, refreezing of infiltrating meltwater can create laterally isolated heat sources of relatively warm snow by release of latent heat on refreezing but it is not possible to create a laterally isolated heat sink in the snow via infiltration of melt. Melting (i.e. local production of liquid as opposed to infiltration) is a heat sink but it does not occur at temperatures below $0^{\circ} \mathrm{C}$ and, in any case, no sensible heat is available within the snow to supply latent heat to melt ice at $0^{\circ} \mathrm{C}$. Wetting of sub-freezing snow at depth is supplied by melt generated at and near the surface by radiative and sensible heating or by rainfall but no melting occurs within snow being brought to $0^{\circ} \mathrm{C}$. We note that the process of wetting initially sub-freezing snow by infiltration is entirely a freezing (exothermic) process and also that melting of snow at $0^{\circ} \mathrm{C}$ cannot act as a heat sink to cool adjacent sub-freezing snow. In summary, isolated warming at depth in a vertical temperature profile may be the product of laterally adjacent refreezing which has not been directly measured but no processes are available to create isolated cooling from infiltration and refreezing.

Sublimation can also act at isolated points in the snowpack. Sublimation can cool snow via absorption of latent heat but any large quantity of sublimation would be driven by large vapor-pressure gradients, which arise under constant pressure primarily as a consequence of 
temperature gradients: a large pre-existing horizontal temperature gradient must be invoked to create conditions for horizontally isolated sublimation. Furthermore, to create an isolated temperature minimum, water vapor would have to be advected far from the site of sublimation without condensing (or else sublimation and condensation occur in close proximity and no net temperature gradient is developed). However, water-vapor transport is driven from warm to cold not vice versa. We do not see a plausible mechanism to develop laterally isolated temperature extrema by sublimation. Sublimation occurs as a consequence of temperature gradients; it does not create them.

In summary of the above, heterogeneous infiltration of meltwater can create warm heterogeneities relative to initial temperatures) but not cold heterogeneities.

\section{Application to refreezing at Amitsulôq, West Greenland}

Heat-transfer terms were calculated from temperatures measured in a vertical profile in snow at an elevation of $800 \mathrm{~m}$ at Amitsulôq. The measurement site slopes at approximately $2^{\circ}$ and is topographically very uniform. The location lies near the equilibrium-line elevation and experiences substantial melt with internal refreezing and freeze-on at the snow-ice contact. Thermistors were installed and the initial stratigraphy was determined on 23 June 1992. Temperatures were recorded using Campbell type 107 thermistors; these have a nominal accuracy of $\pm 0.2^{\circ} \mathrm{C}$ and were calibrated in an ice bath immediately before and after field measurements. Thermistors were installed at 16 levels in the $175 \mathrm{~cm}$ snow layer by inserting thermistor cables horizontally (to avoid drainage along leads) into the undisturbed snow beyond the pit wall. Penetration distances beyond the pit wall were staggered between 100 and $125 \mathrm{~cm}$ and separated horizontally over a $30 \mathrm{~cm}$ range to avoid locating any thermistor immediately above or below a near neighbor. Thermistors were not fixed in position but were allowed to settle with the snow. The changing thermistor positions were estimated and accounted for in the finite-differencing. We prefer to let the thermistors move with the snow, since fixing thermistor positions creates artifact voids and channels below the thermistors as the snow settles past the thermistor. The main pit was back-filled after installation of the thermistors to avoid spurious heating, cooling or meltwater movement due to an open pit wall. The stratigraphy of snow in the back-filled pit is disrupted but we believe the temperature sensors are sufficiently distant from the back-filled snow to avoid errors arising from this source.

Spatial and temporal temperature gradients were calculated by finite-differencing of the temperature data. Temperature data were separated by uniform time intervals $(5 \mathrm{~min})$ but non-uniform spatial intervals. Spatial and temporal finite differences were calculated by central finite differences, allowing for non-uniform spatial intervals. Differencing coordinates denoting thermistor position were adjusted over time by interpolating linearly between initial and final thermistor positions, which were determined at the time of installation and again at excavation (snow settlement is non-linear in time but we cannot determine intermediate thermistor positions well enough to justify more elaborate interpolation than linear). Vertical profiles of snow density $\rho$ were measured at nearby sites periodically during melting and density as a function of depth and time was obtained by linear interpolation between the density profiles measured at intervals during the experiment. Thermal conductivity $k_{\text {th }}$ was estimated as a function of $\rho$ only (Langham, 1981). The heat capacity $C$ is well known. The terms in Equation (1) involving gradients are evaluated as functions of space and time and the difference between those terms is the volumetric internal energy plus error $\left(q^{\prime}\right)$. Errors must be eliminated or estimated and the remaining volumetric rate of internal energy production partitioned into latent-heat release and other sources. After treating known and potential errors, $q^{\prime}$ provides an estimate of energy released by latent heat of fusion, as a function of space and time. The location and timing of ice accumulation through refreezing is determined directly from this.

The initial snowpack on 23 June 1992 was $175 \mathrm{~cm}$ thick and lay on the bare-ice ablation surface from the previous year. Steady summer melting had not yet begun on 23 June at this site, although there had evidently been an isolated melt event some weeks earlier which produced melt-freeze features restricted to a $5 \mathrm{~cm}$ layer between 14 and $19 \mathrm{~cm}$. This layer was covered by a subsequent $14 \mathrm{~cm}$ of snow. The snow temperatures below $5 \mathrm{~cm}$ depth on 23 June were between $-3^{\circ}$ and $-8 \mathrm{C}$. Temperature and stratigraphic measurements were continued for $18 \mathrm{~d}$ to 11 July. The snow thickness diminished from $175 \mathrm{~cm}$ before the onset of melt to $130 \mathrm{~cm}$ at the end of the experiment when all the snow had reached $0^{\circ} \mathrm{C}$.

Snow stratigraphy was mapped in pits to the snow-ice interface. The stratigraphic parameters include profiles of grain-size, shape and morphology, hardness and layer definition. Profiles of both density and liquid-water content were measured at $2 \mathrm{~cm}$ intervals by the full permitivity dielectric method (Sihvola and Tiuri, 1986). Both density and liquid-water content measurements by this dielectric method have accuracies in clean snow comparable to or better than volumetric density measurements or simple dielectric water-content measurements (nominally $\pm 5 \%$ for density and $\pm 2 \%$ for volumetric water content). The stratigraphic parameters were measured in the pit used for installation of thermistors at the time of installation and repeated at intervals during the experiment in snow pits adjacent to the main pit (within c. $10 \mathrm{~m}$ but not closer than c. $3 \mathrm{~m}$ ). The stratigraphy at the main pit was examined again at the end of the experiment when the thermistors were recovered.

\section{Distribution of temperature}

The record of temperature in the snow is shown in Figure 1. The image shows temperatures as colors in a timedepth domain. The image is a $512 \times 512$ unsmoothed resampling of a $16 \times 1024$ raw-data image. The vertical dimension of the image represents depth, from the initial snow surface to $170 \mathrm{~cm}$. The horizontal dimension represents time, with the entire image width covering approximately $11 \mathrm{~d}$ from 23 June to 4 July. The upper surface of 


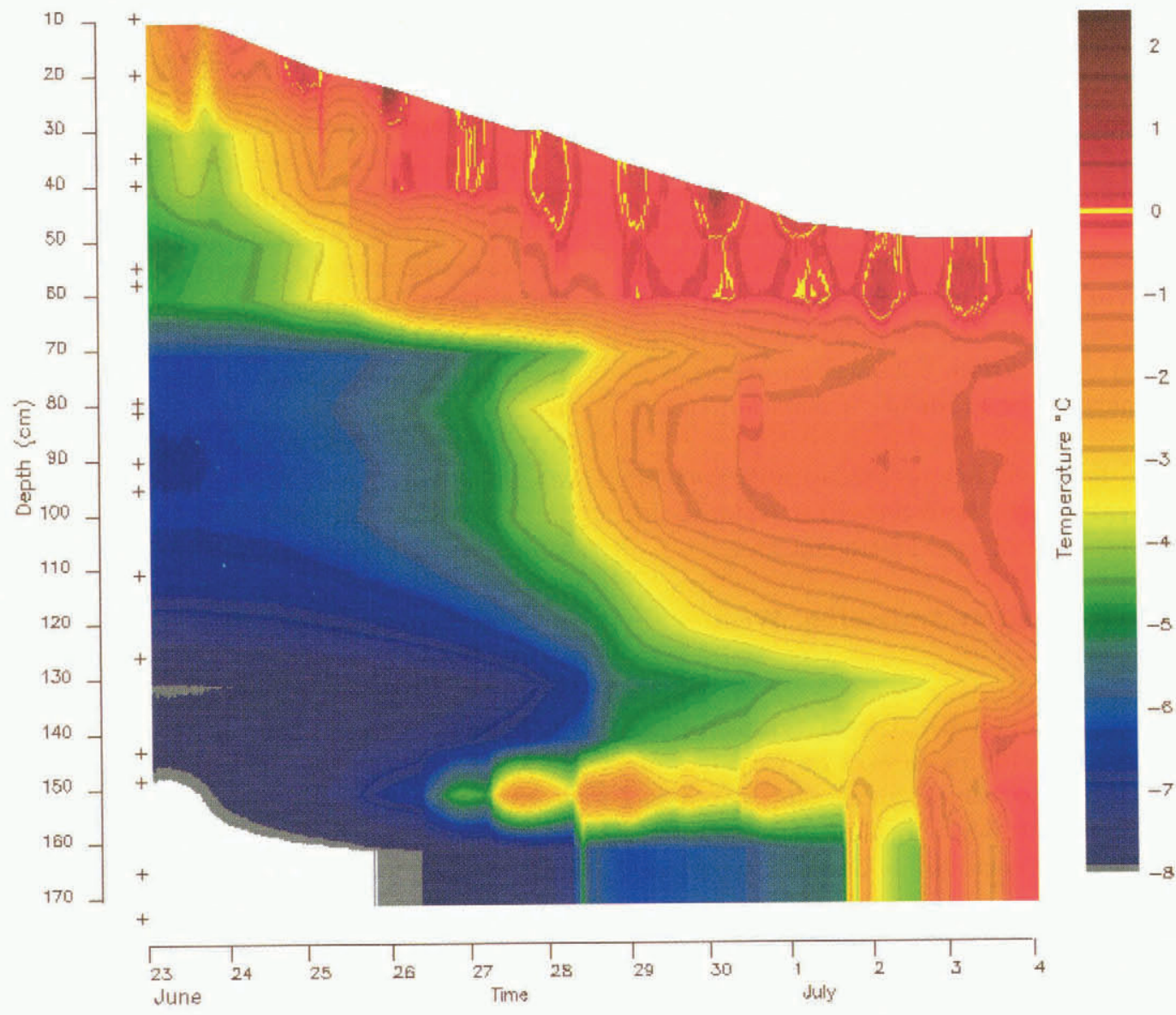

Fig. 1. Temperature as a function of depth and time in snow.

the image descends to the right (advancing time) as the snow surface lowers from melting. Crosses on the lefthand margin mark the initial positions of the thermistors.

The near-surface diurnal warming rises to temperatures above $0^{\circ} \mathrm{C}$ (these areas are distinguished by a bordering band of yellow in Figure 1); this is caused by direct solar heating of thermistors within about $20 \mathrm{~cm}$ of the surface. These thermistors melt open channels as they encounter the descending surface. Once thermistors come to within about $10 \mathrm{~cm}$ of the surface, the temperature records show high-frequency variation, indicating that they are predominantly responding to radiation at the surface and the records are discarded. For this reason, records from the top four thermistors were eliminated as they emerged near the surface during the run of the experiment.

The conspicuous features of the temperature field at depth include a diurnal warm pulse which penetrates from the surface down $20-40 \mathrm{~cm}$, downward propagation of warming at all depths, a broad temperature maximum between 72 and $110 \mathrm{~cm}$, diurnal pulses of warm temperatures at c. $150 \mathrm{~cm}$ (26 June-3 July) and persistent layers of relatively cold temperatures at approximately 70 and $130 \mathrm{~cm}$. The simplest aspects of the temperature record can be explained qualitatively: radiative heating at the surface drives a warm wave which penetrates at an average rate of roughly $14 \mathrm{~cm} \mathrm{~d}^{-1}$. Pulses of heat appear at $150 \mathrm{~cm}$ in advance of the warm wave, evidently caused by the appearance of latent heat of fusion from piped water refreezing at this depth.
Diurnal warming at depth will be seen to coincide with stratigraphic evidence of meltwater refreezing. On the basis of the temperature records alone, one would expect to find ice layers developed at or near $150 \mathrm{~cm}$ starting sometime after 26 June.

\section{Distribution of local internal energy production $q^{\prime}$}

The record of volumetric local internal energy production, $q^{\prime}$ (calculated by Equation (1)), is shown in Figure 2. The time and depth axes are identical to Figure 1; the colors represent $q^{\prime}$, with magnitudes as given on the color scale in units of (latent heat associated with) kilograms of ice frozen per cubic meter per hour.

Figure 2 shows apparent heat sources (red) acting at depths of approximately $30-50,75-85$ and $145-170 \mathrm{~cm}$. The comparatively weak, short-lived heat source at 30 $50 \mathrm{~cm}$ (strongest at c. $35-42 \mathrm{~cm}$ late on 25 June) occurs within the surface layers early in the cycle of strong diurnal heating. The heat source at $75-85 \mathrm{~cm}$ lies within the warm layer at $72-110 \mathrm{~cm}$ in the temperature field, while the heat source at $145-170 \mathrm{~cm}$ corresponds to the warming seen in the temperature field at $150 \mathrm{~cm}$. The heat source at $30-50 \mathrm{~cm}$ is not clearly visible as a maximum in the temperature field, nor is the warm layer at $72-110 \mathrm{~cm}$ obviously a heat source based on temperature alone. The calculation of $q^{\prime}$ brings out the time and location of heat sources which are obvious in the temperature record, such as at $150 \mathrm{~cm}$ depth, but also brings out the heat sources at $30-50$ and $75-85 \mathrm{~cm}$ which 


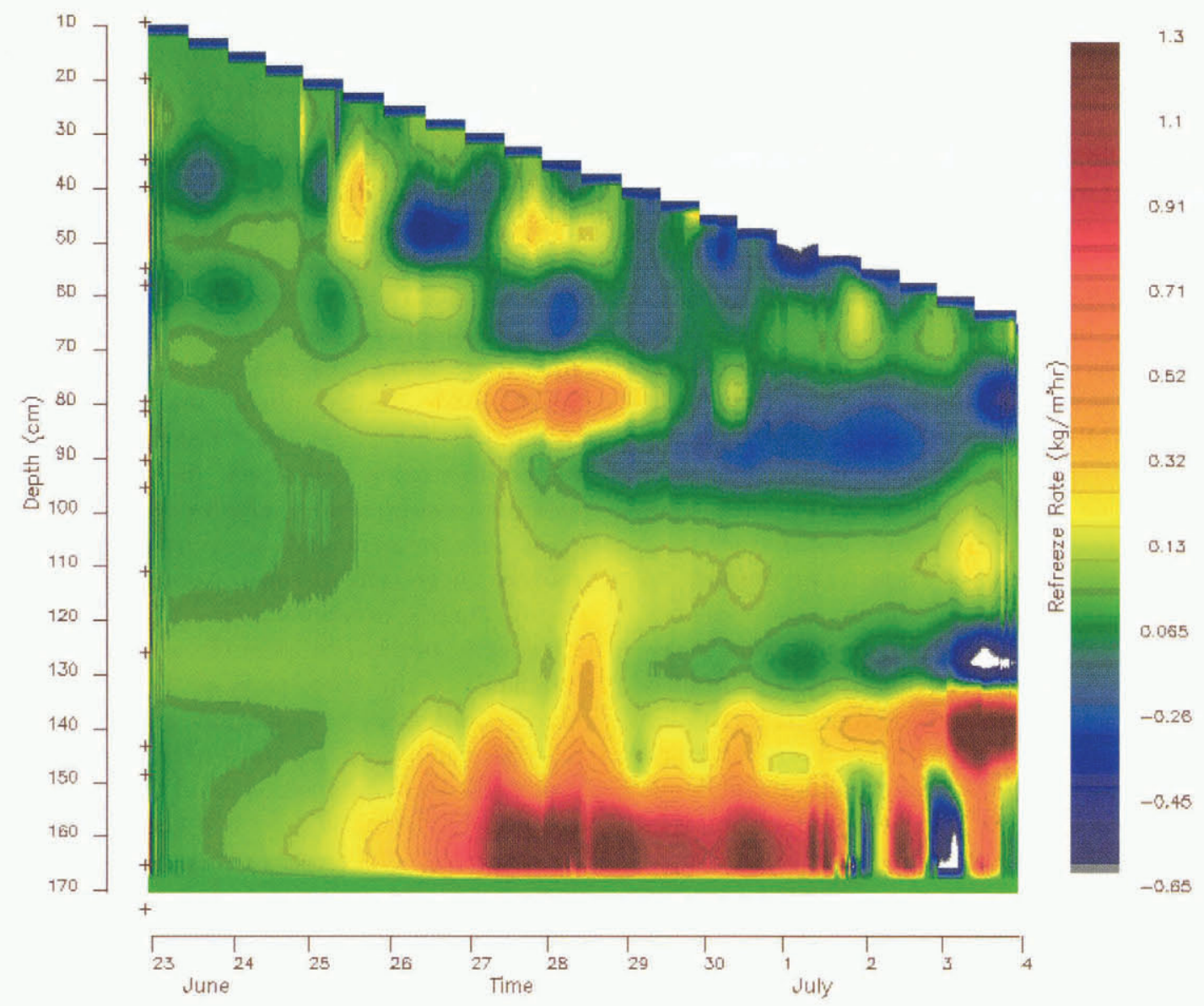

Fig. 2. Local internal energy production as a function of depth and time in snow as calculated from temperature gradients. Units of energy production are expressed in terms of the mass of water frozen to release the equivalent energy as latent heal.

are not at all obvious in the temperature field. These inferences are confirmed by stratigraphic observations made before, during and after infiltration (section VI).

Also visible in Figure 2 are apparent heat sinks, most prominently at $120-130 \mathrm{~cm}$ on 4 July at $130 \mathrm{~cm}$ and 3 July at $165 \mathrm{~cm}$. Weaker sinks appear at 45, 60 and $90 \mathrm{~cm}$ on 26, 27 and 28 June, respectively. The heat sink at 120 $130 \mathrm{~cm}$ corresponds to the layer of persistently cold temperatures at $130 \mathrm{~cm}$ in Figure 1. The presence of the heat sink indicates that the cold layer is not simply snow warming up more slowly than its surroundings but rather that it is warming more slowly than the calculated heat flux into the layer would demand. As discussed above, non-zero $q^{\prime}$ may occur as a consequence of real heat sources and sinks or as a consequence of various possible errors but, since there is no plausible way to form a heat sink at depth in the snow as a consequence of infiltration, we interpret this sink as an artifact of the calculation. We now seek to determine what conditions could cause an artifact heat sink and what effect this could have on the determination of heat sources, which we judge to be real.

Measurements have been made of thermal conductivity of snow as an increasing function of density (Langham, 1981, p.296-97. Grain structure is not necessarily well correlated with density (as seen in the comparison of Figures 4 and 5 below), but grain structure and connectivity is a factor in determining aggregate thermal conductivity (Vries, 1963; Langham, 1981). Anomalously slow warming (apparent heat sink) will result if the actual thermal conductivity in the laver is lower than the thermal conductivity assumed in the calculation of the heat-tranfer terms. A low thermal conductivity may result from highly ordered grain structures which create poor thermal pathways in certain directions. The apparent heat sink at $130 \mathrm{~cm}$ corresponds to depths within unit D where grain structures exist (see section IV) and small air gaps were observed (Fig. 5; 2 July) in unit B in the vicinity of the apparent heat sink at $60 \mathrm{~cm}$. Air gaps would substantially reduce the effective thermal conductivity of the aggregate below what would be calculated for uniform and continuous snow. The anomalously low temperatures of these layers intensifies during the onset of melt, when the grain structure is changing rapidly during densification.

Errors in thermal conductivity will assign spurious magnitudes to $k_{\mathrm{th}} \nabla T$ in Equation (1). If $k_{\mathrm{th}}$ is calculated to be lower than actually exists, then $\nabla \cdot\left(k_{\mathrm{th}} \nabla T\right)$ will not account for the full magnitude of the diffusion actually occurring and the difference will be assigned to $q^{\prime}$. A low calculated $k_{\text {th }}$ at a temperature minimum will retard $k_{\text {th }} \nabla T$ (i.e. measured $T$ rises faster than $k_{\text {th }} \nabla T$ can account for and the result will be an artifact heat source $\left.q^{\prime}\right)$. Similarly, high calculated $k_{\text {th }}$ at a temperature minimum results in an artifact heat sink; high $k_{\text {th }}$ at a temperature maximum results in an artifact source; and low $k_{\text {th }}$ at a temperature maximum results in an artificial sink. In no case, however, can errors in $k_{\text {th }}$ act to deepen a temperature extremum. Errors may act as sinks or sources 
which accelerate or delay the warming of a temperature minimum or cooling of a maximum but cannot act to warm a temperature maximum or cool a minimum.

\section{Estimate of density change from infiltration, refreeze and settlement}

Since local internal energy production $q^{\prime}$ is expressed in terms of the mass of frozen water per unit volume of snow, this quantity can be integrated over time at a fixed depth to estimate the density change over the period of time at that depth occurring as the consequence of refreezing of infiltrated water. Observed changes in snow density between the initial, pre-infiltrated state and the final state comprise settlement and infiltration of water from melt generated higher in the snowpack. Some fraction of the infiltrated water refreezes. These contributions to density change can be estimated from the measurements: increased water content remaining as liquid from measured profiles of water content, refreezing of infiltrated water from $q^{\prime}$ and settlement from changes in thermistor position. Since meltwater is generated near the snow surface, we assume that all liquid water detected at depth was generated at a point higher in the snowpack and is in fact added mass at the point where it is measured.

Figure $3 \mathrm{a}$ shows the refreeze $q^{\prime}$ (integrated over the period 23 June-4 July), measured water content on 4 July and estimated settlement between 23 June and 4 July, all as functions of depth in the snow. The sum of these three quantities is the estimate of density change. Figure $3 \mathrm{~b}$ shows the calculated final density (initial density plus estimated density change) and is compared to the measured final density on 4 July.

Integrated internal energy production is calculated only below $70 \mathrm{~cm}$, since the snow above $70 \mathrm{~cm}$ was lost through melting by 4 July. Agreement between calculated and measured final density is excellent below
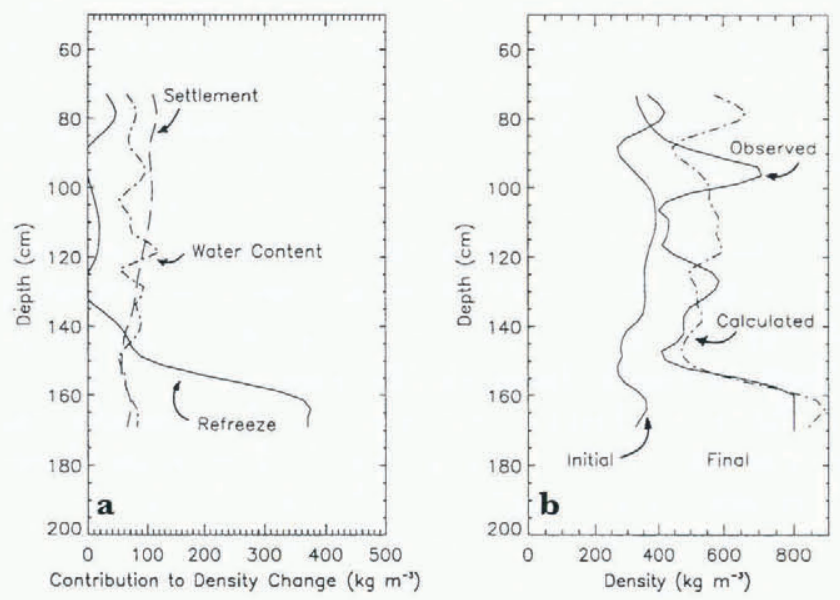

Fig. 3. Total mass refrozen as a function of depth over the period of record of Figures 1 and 2. Vertical coordinate is from original (23 June) surface. a. Relative contributions of increased ice mass through refreezing of infiltrated water, increased water mass through infiltration only and settlement. b. Calculated and observed final density. Calculated mass refrozen is derived from summing the three contributions shown in Figure $3 a$.
$130 \mathrm{~cm}$. Calculated final density is less than measured final density at the maximum at $95 \mathrm{~cm}$ and exceeds measured final density above $95 \mathrm{~cm}$ and between 100 and $130 \mathrm{~cm}$. Referring to Figure 3a, settlement is the principal contribution to calculated final density above $130 \mathrm{~cm}$. An overestimate of density change through settlement (as detected by thermistor motions) is likely in the topmost c. $20 \mathrm{~cm}$ where undetected direct solar heating of the thermistors may have caused them to settle more than the surrounding snow. Liquid-water content is the principal contribution to the density maximum at $100 \mathrm{~cm}$. Settlement is again probably the principal contribution to the overestimate at $100-130 \mathrm{~cm}$, although in this case the possible cause is less clear. Below $130 \mathrm{~cm}$, agreement between calculated and measured density change is very good, with the principal contribution to the change being refreeze (accretion of superimposed ice). The values of density change predicted from settlement as estimated by change in thermistor position appear to be the most unreliable of the three parts of the density-change calculation and this is supported by greater discrepancy between calculated and measured density in the upper part of the snowpack where total displacements were the greatest. This method described here is not highly reliable for accurately predicting density changes but it identifies very clearly the separate processes involved in densification.

\section{STRATIGRAPHIC OBSERVATIONS IN SNOW DURING INFILTRATION}

Stratigraphic inspection of snow stratigraphy before, during and after meltwater infiltration constrains the timing and location of infiltration and refreezing, and may be compared to timing and location of refreezing inferred from temperature measurements. Figures 4 and 5 show the evolving snowpack stratigraphy between 23 June and 10 July. Figure 4 shows profiles of density (dashed line) and liquid-water content (solid line) obtained at $2 \mathrm{~cm}$ intervals on $7 \mathrm{~d}$ during the $17 \mathrm{~d}$ interval. Figure 5 shows the mapped stratigraphy on $6 \mathrm{~d}$ during the same interval. Since these data were taken from different pits in the immediate vicinity of the main pit, some variability exists in depths of layers but the overall pattern of stratigraphy is expected to be strongly correlated in the horizontal and in fact is easily traceable from one pit to another, despite minor differences in the depth of various features from one pit to another.

Initial conditions on 23 June show a sub-freezing dry snowpack with refrozen melt-freeze (MF) structures showing evidence of recent wetting between 14 and $20 \mathrm{~cm}$ and below $95 \mathrm{~cm}$. New snow in the top $14 \mathrm{~cm}$ (unit A) covers the near-surface MF layer between 14 and $20 \mathrm{~cm}$ (unit B). Unit B is evidently a recent melt event, followed by new snow (unit A). Unit C (20-80 cm) shows sintering and preservation of original grain angularities and possibly evidence of MF. Unit D $(80-170 \mathrm{~cm})$ is marked by weak MF with some angularity and weak faceting, with snow below $95 \mathrm{~cm}$ containing stronger $\mathrm{MF}$ features together with faint features of kinetic growth (faceting, faceted grain clusters), and six ice layers below $120 \mathrm{~cm}$. These features indicate water having been 


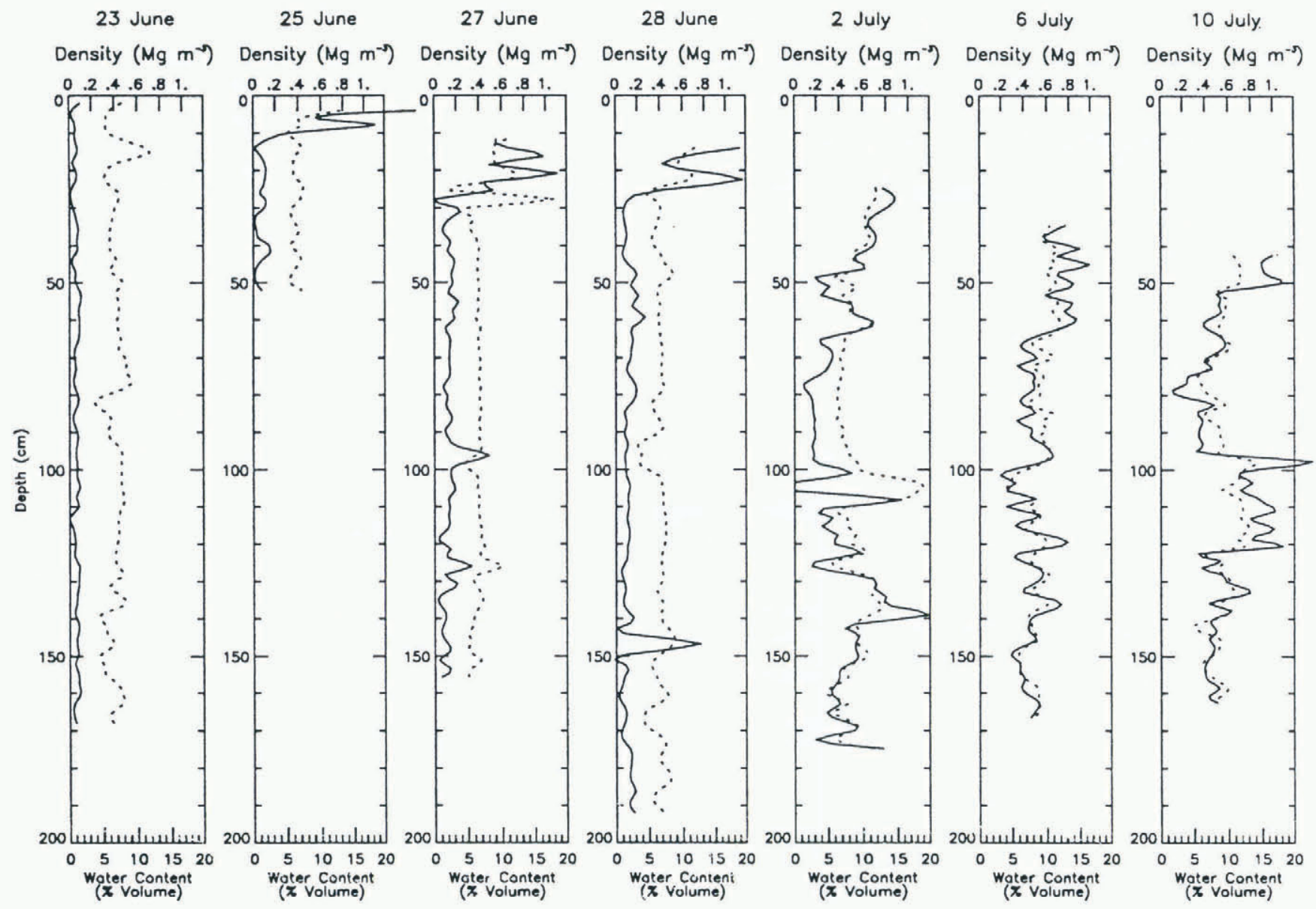

Fig. 4. Profiles of snow density (dashed line) and liquid-water content (solid line) on $7 d$ during the period of record, taken in the immediate vicinity of the temperature-measurement site.

present possibly below $80 \mathrm{~cm}$ and definitely below $95 \mathrm{~cm}$, and we interpret them as the product of an autumn melt event following early accumulation. They cannot be the product of recent melt (contemporaneous with unit B), since sufficient time has elapsed to allow some kinetic growth features to have developed, and since the MF features in unit B on 23 June do not indicate sufficient melting to supply piping to the ice layers below $120 \mathrm{~cm}$.

Prominent layer interfaces are marked by solid lines in Figure 5. Major transitions distinguish the named units: the $\mathrm{B} / \mathrm{C}$ interface is the base of the MF layer; $\mathrm{C} / \mathrm{D}$ marks a distinct increase in grain-size and hardness upon entering the autumn MF features. Dashed lines mark sub-unit interfaces within the major units. Layers in the stratigraphy are not necessarily well correlated with distinct density units but are more often defined by distinct hardness and grain-size. Some relations are visible: unit B in the stratigraphy (Fig. 5) is visible as a peak in density (Fig. 4) at c. $10-18 \mathrm{~cm}$, while the fine-to-coarse transition at $80 \mathrm{~cm}$ appears as a drop and rise in density at that depth. Variations in density below $110 \mathrm{~cm}$ correspond to the sequence of ice layers at and below $120 \mathrm{~cm}$.

Depth profiles of liquid-water content (Fig. 4) from 27 June, 28 June and 2 July clearly show the downward propagation of the wetted surface layer, where liquidwater content exceeds the $5-10 \%$ required in snow for gravity drainage to dominate capillary forces Colbeck and Davidson, 1973). On 27 June, there also appear wetted layers at 95 and $125 \mathrm{~cm}$ depth both in the profile of water content and in the mapped stratigraphy. This is water piped from the stratigraphic break which appears at $30 \mathrm{~cm}$ depth on 27 June (Fig. 5) as an ice layer carrying water on top which formed on a fine-to-coarse transition. The ice layers at depth formed when piped water encountered the stratigraphic breaks seen in the 23 June stratigraphy at 95 (fine-to-coarse transition) and $120 \mathrm{~cm}$ (old ice layer). Another prominent wetted layer appears at $145 \mathrm{~cm}$ on 28 June in the profile of water content and a wet layer appears at the snow-ice interface $(175 \mathrm{~cm})$, starting the accretion of superimposed ice. Water at 145 and $175 \mathrm{~cm}$ was piped from the $95 \mathrm{~cm}$ level, where an ice layer had formed. Piping between these levels was confirmed at a second pit dug on 2 July. A pipe source could be acting again at the $30 \mathrm{~cm}$ level but it is less likely at this time because the near-melting temperature at $30 \mathrm{~cm}$ on 2 July strongly favors uniform downward percolation as opposed to lateral transport to a pipe source.

Following 28 June, the snowpack becomes more uniformly wetted, with liquid-water content rapidly exceeding $5 \%$ everywhere in the column and becoming clearly visible in the stratigraphy. Ice continues to accrete between 95 and $110 \mathrm{~cm}$ and at the snow-ice boundary. By $10 \mathrm{July}$, all snow temperatures are at $0^{\circ} \mathrm{C}$ and freezing of meltwater has ceased except at the snow-ice boundary.

The locations of latent-heat release determined by temperature measurements (Fig. 2) correspond closely to stratigraphic horizons where refreezing is expected (Figs 4 


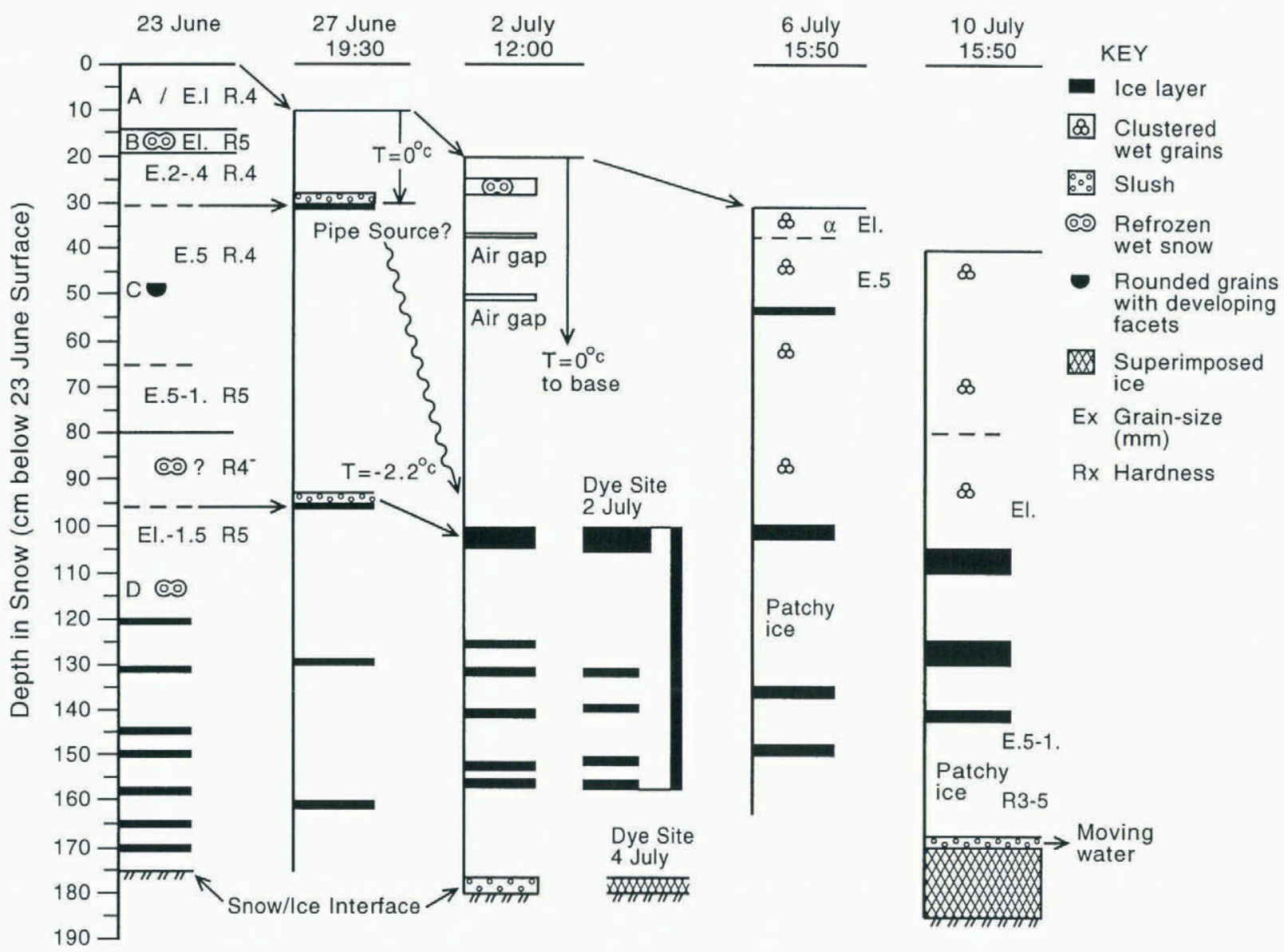

Fig. 5. Sequence of developing stratigraphy during the period of record, taken in the immediate vicinity of the temperaturemeasurement site.

and 5). The heat source at $35-42 \mathrm{~cm}$ late on 25 June is the product of refreezing at the fine-to-coarse transition at $30 \mathrm{~cm}$ on 23 June which appears on 27 June as an ice layer carrying water. Heat appearing at $75-85 \mathrm{~cm}$ is probably associated with refreezing at the fine-to-coarse transition of the C/D layer boundary at $80 \mathrm{~cm}$. A wetted ice layer on 27 June appears at $95 \mathrm{~cm}$ and is assumed to be the same stratigraphic and hydrological horizon appearing at a slightly different depth in the pit dug on 27 June. The broad and intense area of heating between 145 and $170 \mathrm{~cm}$ is associated with superimposed ice formation but it is probably broadened by refreezing at the pre-existing ice layers between $140 \mathrm{~cm}$ and the snowice interface at c. $170 \mathrm{~cm}$.

\section{DOWNSLOPE FLOW AND ONSET OF PIPING}

Is an impermeable horizon required for lateral flow of water? Dye-tracing experiments at Amitsulôq indicate that water can flow laterally downslope within a single stratigraphic unit without an impermeable horizon to block vertical drainage. Lateral distances traveled by meltwater in this way may be tens of meters. The quantity of water which may be moved by lateral transport without an impermeable horizon is unlikely to be significant in terms of glacier run-off but may be significant for initial delivery of water to pipes and therefore determination of spacing and location of pipes.
The development of wetted snow and the downward and downslope movement of water in the snowpack was watched on the grain scale during early surface melting. Wetting derived from radiative melt was visible in the snow as a layer of large $(1 \mathrm{~mm})$ rounded, wetted grains typical of equilibrium-form snow which lies above finer-grained $(0.1-$ $0.2 \mathrm{~mm}$ ) snow with a sharp boundary between. The uppermost few centimeters of the finer-grained snow also contained liquid water but the grains had not yet reached an equilibrium wetted form. For the present discussion, we refer to the upper coarse-grained wetted (equilibrated) layer as the $\alpha$ layer and the lower fine-grained wetted (unequilibrated) layer as the $\beta$ layer. The presence of liquid water in snow limits the penetration depth of solar radiation. Extinction coefficients for melting snow range from 10 to $20 \mathrm{~m}^{-1}$ over pertinent wavelengths (Grenfell and Maykut, 1977) and significant extinction of solar radiation is expected in the upper $10-20 \mathrm{~cm}$. The boundary between the $\alpha$ and $\beta$ layers propagates downward at a rate determined by the penetration depth of radiation and by the grain-ripening process (Colbeck, 1973b), while the downward rate of water flow is determined by gravity drainage at high water content and capillary imbibition at low water content. In particular, gravity drainage controls water flow behind the front where water content is relatively high and gradients in water content are relatively small, while capillary imbibition controls water flow at the wetting front where water content is very low but gradients are high. 
The following sequence of events was observed between 23 and 28 June: on 23 June (before onset of melting), a small quantity of powdered rhodamine dye was spread over about $0.5 \mathrm{~m}^{2}$ at a site approximately $50 \mathrm{~m}$ from the temperature-measurement site. The average slope was approximately $2^{\circ}$ and the topography was uniformly smooth (surface relief had an amplitude of c. $10 \mathrm{~cm}$ and wavelength c. $5 \mathrm{~m}$ ). The stratigraphy of Figure 5 is representative of this site as well. After approximately $2 \mathrm{~h}$, the dye had moved downslope about $1 \mathrm{~m}$. The following morning (24 June), at $16.5 \mathrm{~h}$ after the initial spreading, dye had moved in a continuous plume $8.4 \mathrm{~m}$ downslope. The dye had drained horizontally within the upper, wetted part of the surface (A) layer. The base of the dyed layer corresponded to the base of the downwardpropagating wetted $\beta$ layer and in places had drained out of the overlying $\alpha$ layer. In no place at this time was the base of the dye plume determined by a stratigraphic horizon such as an ice layer or the $\mathrm{A} / \mathrm{B}$ stratigraphic transition. Two days following (25 June), $41.8 \mathrm{~h}$ after the initial dye spreading, the dye plume extended $21.6 \mathrm{~m}$ in the downslope direction and occupied snow between approximately 11 and $17 \mathrm{~cm}$ depth (the depth was not extensively checked at this time in order to leave the snowpack undisturbed). On 26 June, at $71.0 \mathrm{~h}$ after the initial dye spreading, no more downslope motion had been observed but the appearance of the dye as seen from the surface had vanished. Spot checks of the stratigraphy showed the dye lying in several layers down to depths of about $40 \mathrm{~cm}$ but absent from the top $10 \mathrm{~cm}$. Evidently, downslope motion in near-surface layers ceased between 25 and 26 June and was replaced by vertical descent. On 28 June, the region was dug up and the deep stratigraphy examined (Fig. 6). The stratigraphy on 28 June shows that at the up-glacier end of the site, dye drained from the A layer and accumulated below, typically between 10 and $25 \mathrm{~cm}$ depth. Beneath this zone of accumulation several dyed layers appeared (e.g. at downslope distance of $3.0 \mathrm{~m}$ ), delivered from higher layers by pipes initiated at c. $25-30 \mathrm{~cm}$. This was confirmed by pipes observed at downslope distances of 3.0 and $10.0 \mathrm{~m}$. At $34.0 \mathrm{~m}$, the snow was excavated to the snow-ice interface and $30 \mathrm{~cm}$ $(130-160 \mathrm{~cm})$ of dyed superimposed ice was found.

The timing of dye movement correlates with the development of the ice-layer stratigraphy as seen in Figures 4 and 5 . The rapid lateral motion of the dye in the $\alpha$ and $\beta$ layers corresponds to the initial ripening of the near-surface snow in the period following 23 June. The change from lateral to vertical motion of the dye corresponds to the break-up of the uniform wetting front and the development of deep wetted layers (at 95 and $125 \mathrm{~cm}$ ) from piping.

The behavior of the dye elucidates the water movement that is inferred from Figure 5. Between 23 and 27 June, the upper few tens of centimeters of snow ripened and the ripened layer thickened as the produced water moved downwards, apparently uniformly. This uniform ripe layer was laterally continuous and hydraulically connected, allowing lateral downslope water motion. On 27. June, the ripe layer encountered the stratigraphic and
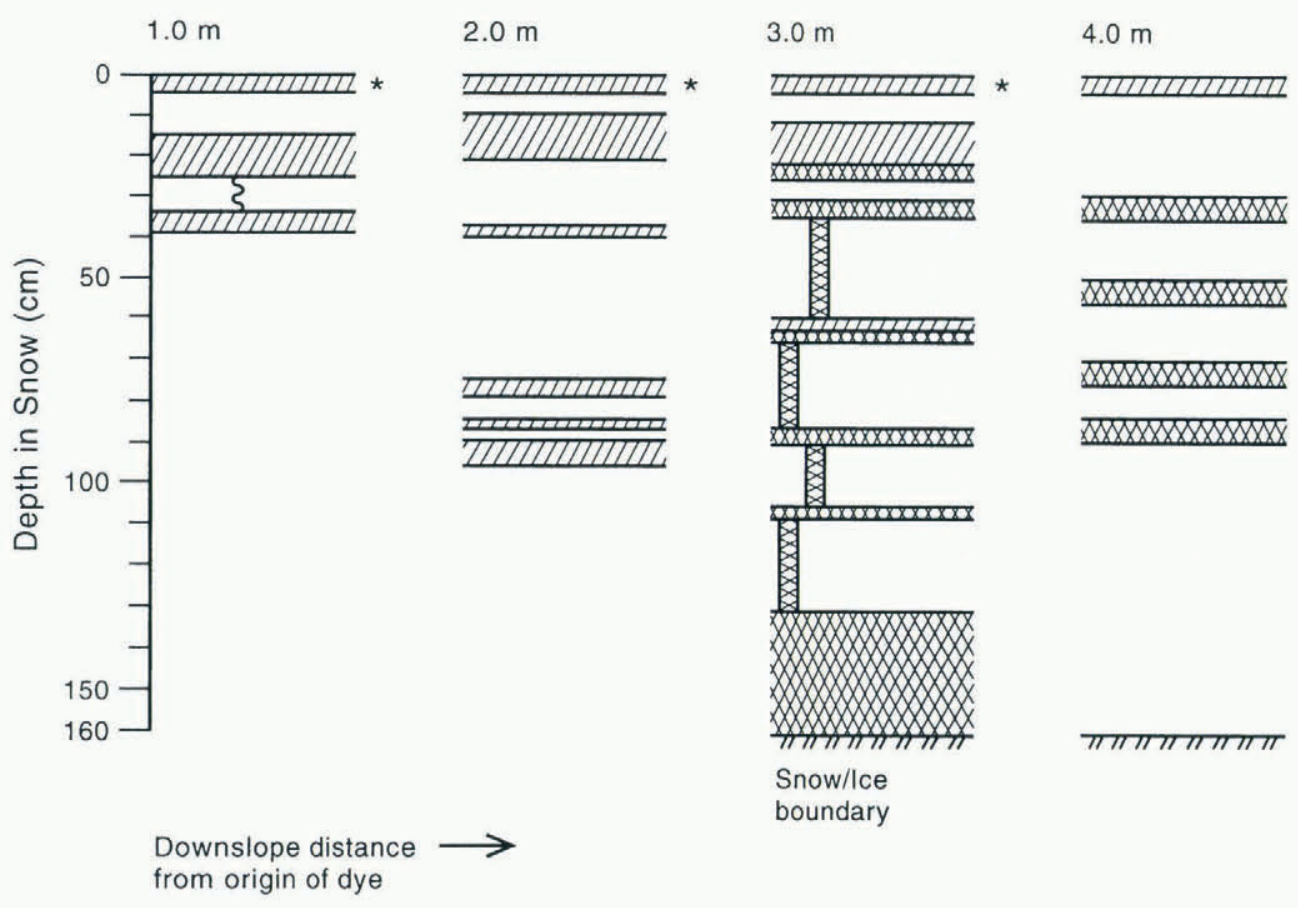

$10.0 \mathrm{~m}$
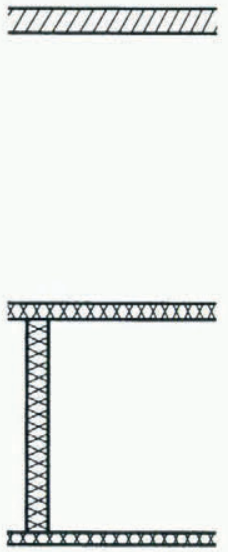

$\begin{array}{cl}\text { KEY: } & \begin{array}{l}\text { Snow marked with dye } \\ \text { Observed vertical drainage } \\ \text { of dye in snow } \\ \text { Ice layer marked with dye }\end{array} \\ \begin{array}{l}\text { Observed ice pipe marked with } \\ \text { dye }\end{array}\end{array}$

NOTE* : Dye seen in top $10 \mathrm{~cm}$ at $16.5 \mathrm{~h}$ was washed down to lower layers by $71.0 \mathrm{~h}$

Fig. 6. Stratigraphy showing passage of dye spread on snow surface. 
hydraulic boundary of the fine-to-coarse transition (Fig. $5)$ at $30 \mathrm{~cm}$. The vertical percolation of water was stopped at this hydraulic boundary and refroze, forming an ice layer and allowing lateral downslope flow to increase. Subsequent break-through of the layer was at discrete points, initiating pipes in the lower cold snow. The pipes descended until the unsaturated flow was blocked by either an hydraulic boundary (at $95 \mathrm{~cm}$ ) or by a preexisting ice layer (at $125 \mathrm{~cm}$ ).

The uniform descent of the wetting front continues as long as there is no strong impediment to downward motion. At a hydraulic boundary to unsaturated flow such as a fine-to-coarse transition of a pre-existing ice layer, the wetting front stops and water content at the barrier increases until a saturation level is reached which allows break-through or until sufficient refreezing occurs to create an impermeable barrier. It is probably during these periods of pooling above hydraulic barriers that maximum lateral transport of water occurs. After breakthrough, the affected region of the snowpack is dominated by vertical water flow with rapid advection of latent heat into the sub-freezing snow surrounding the pipe and into the lower layers of the snowpack. This break-up of the laterally homogeneous wetting front into a heterogeneous system introduces the thermal complexity seen in Figure 1.

\section{INTERPRETATION OF WETTING-FRONT PROPAGATION}

The propagation of the wetting front in the uppermost, warmest layers of the snow proceeds without the formation of distinct ice layers if the snow "cold content" (the specific mass or volume energy required to bring the snow from a given initial sub-freezing temperature to $0^{\circ} \mathrm{C}$ ) is sufficiently small to be removed by latent heat without new infiltrated ice completely filling or isolating pore space (Colbeck, 1976; Pfeffer and others, 1991). No ice layers were encountered in this case above $30 \mathrm{~cm}$. Wet layers (e.g. at $30 \mathrm{~cm}$ in the 23 and 27 June stratigraphy (Fig. 5) formed on stratigraphic breaks where fine-grained snow lies above coarse-grained snow. The fine-to-coarse transition acts as a hydrological obstacle to flow. Water transmitted through the overlying fine-grained snow is retarded at the transition to coarse-grained snow. Colbeck (1973a) described water flow through layers of different grain-size and indicated that fine-grained layers reduced flow velocity because of their reduced intrinsic permeability as given by Shimizu (1970). This conclusion applies to gravity-driven Darcy flow and does not apply to the transient, variable-flux problem of wetting front advance. Wankiewicz (1979) described the FINA (flow impeding, accelerating or neutral) model for classifying stratigraphic barriers to flow. Within this model, fine-to-coarse transitions are categorized as impeding horizons at low flows. The mechanism of impedance is described in Wankiewicz in terms of the pressure required to drive a given flux as a function of unsaturated permeability of the medium. Water advancing into coarse-grained snow encounters higher intrinsic permeability but a greater specific water content is required to achieve an equivalent value of effective saturation. The unsaturated permeability
(Colbeck, 1972; Corey, 1977),

$$
k_{\text {iw }}=k S^{* n},
$$

will be initially low in coarse-grained material since initially low levels of $S^{*}$ will offset the higher value of intrinsic permeability $k$. As water builds up on the finegrained side of such a barrier, increasing saturation increases the head gradient across the barrier, eventually allowing flow across the barrier and increased saturation on the coarse-grained side. Rising saturation increases hydraulic conductivity and after a transient interval a continuous steady flux is achieved across the barrier.

In sub-freezing snow, as saturation is increasing on the fine-grained side of the barrier fed by flow from above, it is also decreasing due to loss of liquid water to freeze-off into the sub-freezing snow. If the cold content is sufficiently small (i.e. the snow temperature is close to freezing), the snow may reach $0^{\circ} \mathrm{C}$ before it is rendered impermeable by the addition of new ice. The required cold content to close off porous snow by refreezing of liquid water is determined simply by the initial temperature and grain-pore geometry (Pfeffer and others, 1990). If the initial snow temperature at the hydraulic barrier is lower than the minimum for pore close-off, an ice layer forms. The processes of hydraulic break-through and pore close-off compete at the barrier to determine whether or not an ice layer forms; if sufficiently high saturation is reached before pore close-off, further water passes the barrier. If water at the barrier freezes sufficiently quickly, then the saturation may be kept below the value required for break-through and further water accumulates on the now impermeable barrier. The interplay between breakthrough and freeze-off depends on snow temperature and grain-pore geometry and also on the influx rate of water to the barrier and the rate of freezing (Pfeffer and others, 1990, equation (3)).

The process described here dictates the conditions under which an ice layer will form in a layered snowpack. Water accumulating on the newly formed ice layer may refreeze and add to the layer thickness; it may also flow laterally along the layer. Colbeck (1974) analyzed the lateral flow of water on impermeable horizons. Lateral variations in the important variables listed above result in break-through at some parts of a barrier and ice layers at other parts. These differences may be seen throughout snowpacks which have experienced infiltration and refreezing. Extensive break-through and limited icelayer formation results in isolated lenses of ice along a stratigraphic interface, while extensive ice-layer formation and limited break-through results in a typical ice layer: nearly continuous ice perforated with many holes.

\section{DISCUSSION}

Temperature measurements in snow during melting combined with observations of changes in stratigraphy give a detailed picture of the progressive wetting of initially sub-freezing snow. Production of water at the surface is initially very uniform laterally during direct solar heating (development of the $\alpha$ layer) and the onset of drainage (development of the $\beta$ layer) is also laterally 
uniform. Heterogeneous flow develops as vertically draining water encounters variable hydraulic conductivities in the snow. The variable hydraulic conductivity arises initially from variable intrinsic permeability associated with density and grain structures developed by depositional and diagenetic processes. Hydraulic conductivity is further affected by refreezing (affecting porosity and intrinsic permeability) and by changes in water content (affecting unsaturated permeability). Four essential processes are evident:

1. Capillary imbibition acts to move the first water from wetted to unwetted snow. This process is visible in the production of the $\beta$ layer but acts at all wetting fronts. If flow of water occurs only by gravity drainage at water contents above "irreducible" or "residual" saturation, then no mechanism would exist for introducing water into dry snow. The concept of residual saturation originated in soils, where a minimum water content - that not extracted by gravity drainage - is assumed to exist throughout the material. Sub-freezing snow is initially dry and the terms "irreducible" and "residual" saturation are misleading in concept. The term "residual" saturation is meaningful in the way it was used by Colbeck and Davidson (1973), i.e. the water retained by capillary forces after gravity drainage of fully saturated snow. It is also meaningful in that it represents the water content at which capillary forces and gravity are equal in magnitude. In the wetting process, however, water content rises continuously from zero to "residual" by capillary processes and above "residual" by a combination of capillary and gravity forces. A change to terminology more consistent with the pendular and funicular regimes of flow (Colbeck, 1973b) would be desirable. Simple modeling of wetting of cold snow can be achieved by treating the wetting front as a discontinuous front where water content jumps from zero to residual (e.g. Colbeck, 1976). This approach works well for the prediction of the delay in run-off from a snowpack following the onset of melt but does not adequately represent the physics involved in the development of internal structures by freezing in the snow during wetting.

2. Conductive pathways can develop simply by wetting or by a combination of wetting and freezing. The presence of water along any path increases hydraulic conductivity along that path (relative to drier neighboring snow) by increasing unsaturated permeability. Additional water introduced along this path will flow along the wetted path in preference to drier neighboring snow. Increased flux into the wetted pathway further increases unsaturated permeability until saturation is reached. Refreezing of a wetted horizon may form an impermeable barrier to continued flow in the vertical but allow greater flow in the horizontal by pooling of water content along the horizon. Wetting of a vertical pathway (pipe) creates a high-conductivity path for further flow.

In sub-freezing snow, lateral expansion of a pipe (increase in pipe diameter) must be accomplished by refreezing on the pipe perimeter to remove initial cold content (note that the perimeter cannot be warmed by refreezing in the wetted pipe core since the wetted core is fixed at $0^{\circ} \mathrm{C}$ ). This is an energy barrier to lateral expansion of the pipe and acts along with gravity to focus the thermal energy of the pipe in the vertical direction. Refreezing at the pipe perimeter may also limit the pipe size if refreezing is sufficient to close off the pore matrix; however, sufficient water input at the top of the pipe may overflow the refrozen perimeter and allow continued lateral wetting outside the perimeter.

3. Discontinuities in grain structure can present hydraulic barriers to flow. The predominant barrier in the environment studied here appears to be fine-to-coarse transitions in grain-size, where fine-grained snow lies on top of coarse-grained snow. This corresponds to fine-to-coarse impeding horizons described in the FINA model (Wankiewicz, 1979). Saturated layers almost invariably develop along such horizons. As water content rises on the fine-grained side of the transition, hydraulic conductivity also increases and lateral flow along the horizon is facilitated. Lateral flow diverts water from strictly vertical flow and, if a more conductive vertical pathway across the fine-tocoarse transition is encountered at some laterally displaced location, vertical flow resumes as a pipe and is enhanced by wetting as in (2) above.

4. Refreezing interacts with all the processes described above and, in the case of formation of ice layers, occurs as a consequence of internal refreezing rather than freeze thaw cycles propagating from the surface. Conversion of water to ice affects flow in three ways: (1) water content is reduced; (2) porosity is reduced; (3) temperature is increased. Initial wetting by imbibition is retarded by refreezing until the snow temperature is brought to $0^{\circ} \mathrm{C}$. This is the process identified as the "dynamic zone" by Pfeffer and others (1990). Refreezing of wetted layers at fine-to-coarse transitions creates the possibility that an ice layer will form at the transition and may act to seal some conductive bridges across transitions which could otherwise form pipe sources.

\section{ACKNOWLEDGEMENTS}

We should like to thank the Geological Survey of Greenland and O. Olesen for their generous contribution of time and for the use of their facilities at Tasersiaq, and the Polar Ice Coring Office for logistical support between the U.S.A. and Sondrestrom, Greenland. M.F. Meier, R.J. Braithwaite and R.M. Koerner contributed valuable comments in the course of many discussions. We also thank D. McClung and two anonymous referees for careful reviews of an earlier version of this work, and D. Horning for extensive field assistance. This work was supported by DOE grant No. DE-FG02-90ER61078.

\section{REFERENCES}

Alley, R. B. 1988. Concerning the deposition and diagenesis of strata in polar firn. J. Glaciol., 34(118), $283-290$.

Alley, R. B. and S. Anandakrishnan. 1995. Variations in melt-layer 
frequency in the GISP2 ice core: implications for Holocene summer temperatures in central Greenland. Ann. Glaciol., 21, 64-70.

Ambach, W. 1989. Effects of climatic perturbations on the surfaceablation regime of the Greenland ice sheet, West Greenland. J Glaciol., 35 (121), 311-316.

Arpaci, V.S. 1966. Conduction heat transfer. Reading, MA, AddisonWesley.

Benson, C.S. 1962. Stratigraphic studies in the snow and firn of the Greenland ice sheet. SIPRE Res, Rep. 70.

Bindschadler, R.A. 1985. Contribution of the Greenland ice cap to changing sea level: present and future. In Glaciers, Ice Sheets, and Sea Level: Effect of a CO-induced Climatic Change, Report of a Workshop held in Seattle, Washington, September 13-15, 1984. Washington, DC, U.S. Department of Energy. Office of Energy Research, 258-266.

Braithwaite, R.J., M. Laternser and W. T. Pfeffer. 1994. Variations of near-surface firn density in the lower accumulation area of the Greenland ice sheet, Pâkitsoq, West Greenland. J. Glaciol., 40(136), $477-485$.

Colbeck, S. C. 1972. A theory of water percolation in snow. F. Glaciol., $11(63), 369-385$.

Colbeck, S. C. 1973a. Effects of stratigraphic layers on water flow through snow. CRREL Res. Rep. 311.

Colbeck, S. C. 1973b. Theory of metamorphism of wet snow. CRREL Res. Rep. 313.

Colbeck, S. C. 1974. Water flow through snow overlying an impermeable boundary. Water Resour. Res., 10(1), 119-123.

Colbeck, S. C. 1976. An analysis of water flow in dry snow. Water Resour. Res., $12(3), 523-527$.

Colbeck, S. C. 1991. The layered character of snow covers. Rev. Geophys., 29 (1), $81-96$.

Colbeck, S.C. and G. Davidson. 1973. Water percolation through homogeneous snow. International Association of Hydrological Sciences Publication 107 (Symposium at Banff 1972 - Role of Snow and Ice in Hydrology), Vol. 1, 242-257.

Conway, H. and R. Benedict. 1994. Infiltration of water into snow. Waler Resour. Res., 30(3), 641-649.

Corey, A. T. 1977. Mechanics of heterogeneous fluids in porous media. Fort Collins, CO, Water Resources Publications.

Gow, A.J. 1965. On the accumulation and seasonal stratification of snow at the South Pole. J. Glaciol., 5(40), 467-477.

Grenfell, T.C. and G. A. Maykut. 1977. The optical properties of ice and snow in the Arctic Basin. J. Glaciol., 18 80), 445 463.

Illangasekare, T.H., R.J. Walter, Jr, M. F. Meier and W. T. Pfeffer. 1990. Modeling of meltwater infiltration in subfreezing snow. Water Resour. Res., 26(5), 1001-1012.

Jordan, R. 1991. A one-dimensional temperature model for a snow cover: technical documentation for SNTHERM.89. CRREL Spec. Rep. 91-16.

Kocrner, R. M. 1970. The mass balance of the Devon Island ice cap, Northwest Territories, Canada, 1961-66. J. Glaciol., 9 (57), 325-336.

Koerner, R. M., B. T. Alt, J.C. Bourgeois and D. A. Fisher. 1991. Canadian ice caps as sources of environmental data. In Weller, G., C. L. Wilson and B. A. B. Severin, eds. International Conference on the Role of the Polar Regions in Global Change: proceedings of a conference held June 11-15, 1990 at the University of Alaska Fairbanks. Volume II. Fairbanks, AK, University of Alaska. Geophysical Institute/Center for Global
Change and Arctic System Research, 576-581.

Langham, E.J. 1981. Physics and properties of snowcover. In Gray, D. M. and D.H. Male, eds. Handbook of snow: principles, processes, management and use. Toronto, Ont., Pergamon Press Canada Ltd., 275-337.

Marsh, P. and M. -k. Woo. 1984a. Wetting front advance and freezing of meltwater within a snow cover. 1. Observations in the Canadian Arctic. Water Resour. Res., 20(12), 1853-1864.

Marsh, P. and M. -k. Woo. 1984b. Wetting front advance and freezing of meltwater within a snow cover. 2. A simulation model. Water Resour. Res., 20 (12), 1865-1874.

Müller, F. 1962. Zonation in the accumulation area of the glaciers of Axel Heiberg Island, N.W.T., Canada. J. Glaciol., 4(33), 302-311.

Müller, F. 1976. On the thermal regime of a High-Arctic valley glacier. 7. Glaciol., 16 74), 119-133.

Ohmura, A. and 8 others. 1991. Energy and mass balance during the melt season at the equilibrium line altitude, Paakitsoq, Greenland ice sheet $\left(69^{\circ} 34^{\prime} 25.3^{\prime \prime}\right.$ North, $49^{\circ} 17^{\prime} 44.1^{\prime \prime}$ West, 1175 ma.s.l.). Zürich, Eidgenssösche Technische Hochschule. Department of Geography. (ETH Greenland Expedition. Progress Report 1: April 1989 to February 1991.)

Olesen, O. B. 1982. Establishment of a new survey station at Tasersiaq. Gronlands Geologiske Undersegelse. Rapport 110, 86-88.

Ostrem, G. and M. Brugman. 1991. Glacier mass balance measurements. A manual for field and office work. Saskatoon, Sask., Environment Canada. National Hydrology Research Institute. (NHRI Science Report 4.)

Pfeffer, W. T., T.H. Illangasekare and M.F. Meier. 1990. Analysis and modeling of melt-water refreezing in dry snow. f. Glaciol., 36 (123), 238- 246.

Pfeffer, W. T., M. F. Meier and T.H. Illangasekare. 1991. Retention of Greenland runoff by refreezing: implications for projected future sea level change. 7. Geophys. Res., 96(C12), 22,117-22,124.

Sharp, R. P. 1951. Meltwater behavior in firn on upper Seward Glacier, St. Elias Mountains, Canada. International Association of Scientific Hydrology Publication 32 General Assembly of Brussels 1951-Snow and Ice), 246-253.

Shimizu, H. 1970. Air permeability of deposited snow. Contrib. Inst. Low Temp. Sci., Ser. A 22.

Sihvola, A. and M. Tiuri. 1986. Snow fork for field determination of the density and wetness profiles of a snow pack. IEEE Trans. Geosci. Remote Sensing, GE-24 (5), 717-721.

Sturm, M. and J. Holmgren. 1993. Rain-induced water percolation in snow as detected using heat flux transducers. Water Resour. Res., 29 (7), 2323-2334.

Vries, D. A. de. 1963. Thermal properties of soils. In Wijk, W. R. van, ed. Physics of plant environment. Amsterdam, North Holland Publishing Co., 210-235.

Wakahama, G., D. Kuroiwa, T. Hasemi and C. S. Benson. 1976. Field observations and experimental and theoretical studies on the superimposed ice of McCall Glacier, Alaska. f. Glaciol., 16(74), $135-149$.

Wankiewicz, A. 1979. A review of water movement in snow. In Colbeck, S. C. and M. Ray, eds. Proceedings of a meeting on Modeling of Snow Cover Runoff, 26-28 September 1978, Hanover, New Hampshire. Hanover, NH, U.S. Army Corps of Engineers. Cold Regions Research and Engineering Laboratory, 222252. 